JURNAL 『ERKNOSAINS

VOLUME 2

No. 1, 22 Desember 2012

Halaman 1-70

\title{
SPECIES COMPOSITION OF AMPHIBIAN IN GUNUNGKELIR STREAM, JATIMULYO VILLAGE, KULON PROGO
}

\author{
Tony Febri Qurniawan dan Trijoko \\ Laboratorium Taksonomi Hewan \\ Fakultas Biologi Universitas Gadjah Mada \\ Email: tony_qurniawan@yahoo.com
}

\begin{abstract}
Gunungkelir stream is located in Jatimulyo village, western part of Daerah Istimewa Yogyakarta Province. The ecosystem that surrounds Gunungkelir stream looks natural and unpolluted, it is possible for good living environment of amphibians. However, the database about diversity of Amphibians in Gunungkelir stream has not been revealed. This research was done to study species diversity, species richness, species composition and distribution of amphibians in Gunungkelir stream as an effort to support the sustainability of amphibians live from extinction. The research was done on January-May 2009, at night. The VES (Visual Encounter Survey) method with line transects $250 \mathrm{~m}$ were used. A total 11 species of amphibians from 6 different amphibia families were identified. Phrynoidis aspera, Leptobrachium hasseltii and Hylarana chalconota are dominant species. The higest percentage of amphibians population was tadpole (38\%), followed by male (35\%), female (21\%), and the least were juvenile (6\%). During the survey, different species of amphibians were observed with their own range of spatial distribution.
\end{abstract}

Keywords : Amphibi, community structure, Gunungkelir stream

\begin{abstract}
ABSTRAK
Sungai Gunungkelir terletak di wilayah paling barat Propinsi Daerah Istimewa Yogyakarta. Kondisi lingkungan di sekitar sungai Gunungkelir terlihat masih alami dan belum tercemar, sehingga memungkinkan hidup beranekaragam amfibi. Akan tetapi, data mengenai keanekaragaman amfibi yang hidup disekitar sungai tersebut masih belumada. Penelitian ini bertujuan untuk mengetahui kemelimpahan jenis, kekayaan jenis, komposisi jenis, dan distribusi amfibi yang hidup di sungai Gunungkelir sebagai salah satu upaya menjaga kelestarian amfibi dari kepunahan. Penelitian dilakukan dari Januari - Mei 2009 secara aktif pada malam hari. Metode yang digunakan adalah metode VES (Visual Encounter Survey) yang dikombinasikan dengan transek 250 meter. Total 11 jenis amfibi telah berhasil diidentifikasi, yang terdiri dari 6 famili amfibi yang berbeda. Phrynoidis aspera, Leptobrachium hasseltii dan Hylarana chalconota merupakan jenis yang paling melimpah. Persentase populasi amfibi paling besar berupa berudu (38\%), selanjutnya jantan (35\%), betina (21\%), dan paling sedikit berupa juvenil (6\%). Dari hasil pengamatan ternyata setiap jenis amfibi memiliki distribusi spasial masing- masing.
\end{abstract}

Kata kunci : Amfibi, struktur komunitas, sungai Gunungkelir 


\section{PENGANTAR}

Indonesia merupakan negara kedua terbesar di dunia akan keanekaragaman hayati, baik flora, dan fauna. Diperkirakan dari seluruh jumlah flora dan fauna yang ada di dunia 17\% berada di Indonesia (Groobridge, 1992). Salah satu jenis keanekaragaman hayati dari kelompok fauna yang ada di Indonesia adalah amfibi.

Amfibi merupakan salah satu kelompok fauna yang kurang dikenal dalam keanekaragaman hayati. Di dalam ekosistem, amfibi memiliki peranan yang penting dalam menjaga keseimbangan lingkungan dan memiliki nilai ekologis yang cukup tinggi. Kurangnya peneliti dan penelitian tentang amfibi membuat keberadaan anura cenderung terabaikan. Padahal amfibi adalah kelompok binatang yang sangat peka terhadap perubahan lingkungan seperti pencemaran air, pengrusakan habitat asli, introduksi spesies eksotik, penyakit, dan parasit (Stebbins \& Cohen, 1995; Carrey, dkk: 2001; Corn, 2005; Cushman, 2006; Kusrini, dkk: 2008) serta perubahan iklim (Blaustein, dkk dalam Semlitsch, 2003). Kepekaan fauna ini terhadap lingkungan menjadikannya sebagai indikator perubahan lingkungan yang potensial. Oleh karena itu, amfibi merupakan fauna yang rentan terhadap kepunahan dan peka terhadap perubahan lingkungan. Secara nyata terbukti telah terjadi penurunan populasi dan keragaman jenis amfibi di dunia sejak 1980-an (Gardner, 2001). Sedikitnya 1.856 jenis amfibi yang terancam punah, 113 jenis tidak ditemukan lagi akhir-akhir ini (Stuart, dkk: 2004).

Berdasarkan data IUCN (2008) tercatat 39 jenis amfibi dari Indonesia yang telah masuk dalam kategori daftar merah atau red list, diantaranya terdapat 33 jenis berstatus genting atau threated. Di Pulau Jawa diketahui terdapat 37 jenis katak dan kodok. Dari jumlah tersebut, 15 jenis di antaranya bersifat endemik, 2 jenis berstatus kritis atau critically endangered, serta 3 jenis di antaranya saat ini sudah tidak ditemukan lagi. Tiga jenis tersebut belum sempat dipelajari lebih dalam lagi (Kurniati, 2006; Iskandar, 2006). Kenyataan inilah yang mendorong untuk dilakukannya penelitian mempelajari komposisi spesies amfibi di sepanjang aliran sungai Gunung Kelir Desa Jatimulyo, Kabupaten Kulon Progo. Tujuan penelitian ini adalah untuk mengungkap keanekaragaman, kekayaan, dan distribusi jenis amfibi yang terdapat di lokasi penelitian

Pemilihan sungai Gunungkelir sebagai lokasi penelitian dikarenakan kondisi lingkungan di sekitar sungai Gunungkelir terlihat masih alami dan belum tercemar, sehingga memungkinkan hidup beranekaragam jenis amfibi. Selain itu lokasi ini belum pernah dikaji mengenai keanekaragaman hayati khususnya amfibi yang ada di sana. Hasil penelitian ini diharapkan dapat memberikan informasi mengenai data keanekaragaman, kekayaan, status, dan komposisi jenis serta distribusi jenis amfibi yang terdapat di sepanjang aliran sungai Gunung Kelir sebagai salah satu upaya dalam melengkapi data keanekaragaman herpetofauna di Yogyakarta.

Bertepatan dengan musim penghujan yaitu pada bulan Januari- Mei 2009 secara aktif nokturnal (dari pukul 19.00-23.00 WIB) di sepanjang aliran sungai Gunungkelir dengan empat lokasi sampling sebagai berikut:

1. Dusun Banyunganti, terletak pada posisi $S 07^{\circ} 45^{\prime} 32.4^{\prime \prime}$ dan E $110^{\circ} 06^{\prime} 40.9^{\prime \prime}$ dengan ketinggian $787 \mathrm{mdpl}$. Bagian hulu sungai berupa mata air yang muncul dari dalam goa. Sungai ini dijadikan sumber air bersih bagi penduduk di sekitarnya. Vegetasi riparian di sekitar sungai rapat bahkan badan sungai tertutupi kanopi. Lebar dan kedalaman sungai bervariasi serta banyak sekali terdapat teluk dan air terjun kecil.

2. Perbatasan dusun Banyunganti dengan dusun Kembang, yang berada pada posisi S $07^{\circ} 45^{\prime} 53.5^{\prime \prime}$ dan E $110^{\circ} 07^{\prime} 02.8^{\prime \prime}$ dengan ketinggian 647 mdpl. Lebar dan kedalaman sungai bervariasi. Secara 
umum topografi sungai ini agak curam serta masih banyak terdapat jeluk dan air terjun kecil. Vegetasi riparian masih rapat, dan badan sungai banyak yang tertutupi kanopi.

3. Dusun Kembang. Lokasi terletak pada posisi S $07^{\circ} 45^{\prime} 05.3^{\prime \prime}$ dan E $110^{\circ} 08^{\prime} 44.4^{\prime \prime}$ dengan ketinggian 599 mdpl. Secara umum topografi sungai ini agak lebih landai serta banyak sekali terdapat jeluk yang dalam. Di hulu sungai terdapat air terjun dan sisi sebelah kiri terdapat tebing. Vegetasi riparian dibagian hulu sangat sedikit sedangkan dibagian lainnya agak rapat.

4. Dusun Pringtali, terletak pada posisi S $07^{\circ} 40^{\prime} 31.9^{\prime \prime}$ dan E $110^{\circ} 09^{\prime} 12.9^{\prime \prime}$ dengan ketinggian $415 \mathrm{mdpl}$. Secara umum topografi sungai ini landai serta banyak sekali terdapat batu-batu besar. Vegetasi ripariannya sedikit dan sungai menjadi semakin lebar, sehingga badan sungai tidak tertutupi kanopi (terbuka).

Pelaksanaan sampling menggunakan metode VES (Visual Encounter Survey) dengan line transect 250 meter di mana setiap 10 meter ditandai dengan bendera bernomer, jadi terdapat 25 transek dipasang disetiap lokasi. Transek dipasang disepanjang tepian sungai pada siang hari sebelum sampling dilakukan. Sampling dilakukan pada malam hari. Penyisiran dan pencarian anura dilakukan $15 \mathrm{~m}$ kanan dan kiri sungai sepanjang jalur transek yang dipasang. Pustaka yang digunakan sebagai rujukan untuk mengidentifikasi antara lain: Kampen (1923) dan Iskandar (1998). Sedangkan penamaan spesies merujuk pendapat dari Iskandar (2006), (Frost, dkk :2006), dan IUCN (2008).

Data yang diperoleh dan dianalisis menggunakan indeks diversitas Shannon Weaver dan indeks dissimilaritas Bray Curtis dengan menggunakan rumus sebagai berikut:
Indeks diversitas dari Shannon Weaver

$H^{\prime}=-\sum \frac{n_{i}}{N} \times \ln \frac{n_{i}}{N}$

Keterangan :

$\mathrm{H}^{\prime}$ : Indeks keanekaragaman Shannon-Wiener

$n_{i} \quad$ : Jumlah individu jenis ke-i

$\mathrm{N}$ : Jumlah individu seluruh jenis

Menurut Brower \& Zarr (1997) indeks diversitas dikatakan tinggi jika nilainya lebih dari 2,0 dan sedang jika nilainya antara 1,5-2,0 sedangkan rendah jika nilainya antara 1,0-1,5 dan sangat rendah jika kurang dari 1,0.

Indeks dissimilaritas Bray Curtis

$B C_{i j}=\frac{S_{i}+S_{j}-2 C_{i j}}{S_{i}+S_{j}}$

Keterangan :

$\mathrm{BC}_{\mathrm{ij}} \quad$ :Indeks dissimilaritas Bray Curtis

$S_{i \text { atau }} S_{j}$ :Jumlah individu jenis pada lokasi i atau $j$

$\mathrm{C}_{\mathrm{ij}} \quad$ :Jumlah individu yang hanya ada disalah satu tempat saja

Menurut Field \& McFarlane (1968) indeks Bray Curtis jika nilainya beriksar antara 0 hingga 1 . Nilai semakin mendekati 1, maka komposisi spesies di antara kedua tempat semakin berbeda.

Analisis data menggunakan bantuan program SPSS 16.0. Untuk mengetahui adanya sexual dimorphisme dilakukan T-test dengan tingkat kepercayaan 99\% antara SVL jantan dengan betina. Sedangkan data sekunder parameter lingkungan berupa kerapatan vegetasi, lebar sungai serta suhu air dan udara diukur di setiap lokasi sampling dan dianalisa terhadap kekayaan jenis dengan uji korelasi Pearson dengan tingkat kepercayaan 95\%. 


\section{PEMBAHASAN}

Total telah berhasil teridentifikasi 11 jenis amfibi yang terdiri dari 2 jenis anggota famili Bufonidae, 2 jenis anggota famili Rhacophoridae, 1 jenis anggota famili Megophridae, 1 jenis anggota famili Microhylidae, 2 jenis anggota famili Ranidae, dan 3 jenis anggota famili Dicroglossidae. Data hasil perhitungan indeks diversitas tersaji pada gambar 1 sebagai berikut:

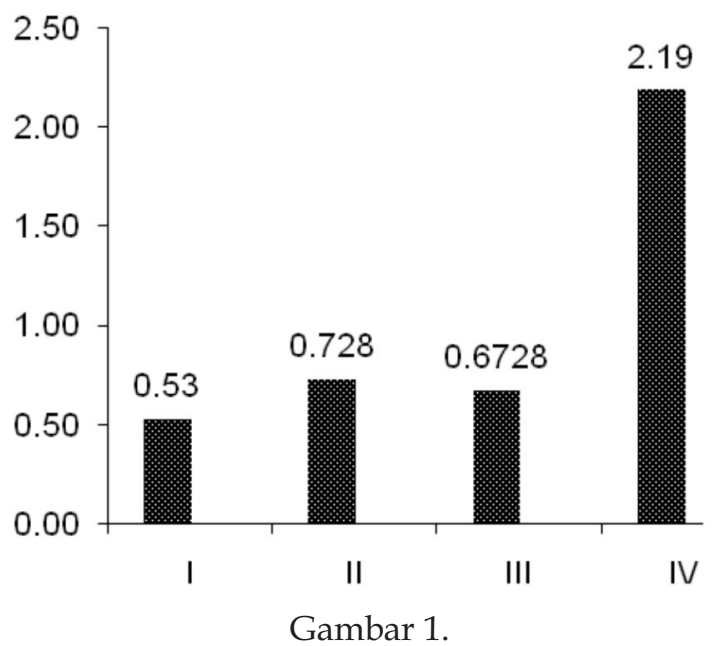

Hasil perhitungan indeks diversitas Shanon Weiner ( $\left.\mathrm{H}^{\prime}\right)$ Keterangan: 1) Banyunganti, 2) Perbatasan, 3) Kembang dan 4) Pringtali

Karakteristik morfologi dan jumlah populasi tiap jenisnya dapat dilihat lebih jelas pada tabel 1 di bawah ini.

Tabel 1.

Komposisi jenis anura di DAS Gunung Kelir beserta karakteristik morfologinya

\begin{tabular}{|c|c|c|c|c|c|c|}
\hline \multirow{2}{*}{ Spesies } & \multirow{2}{*}{$\mathrm{N}$} & \multicolumn{2}{|c|}{ SVL $(\mathrm{cm})$} & \multirow{2}{*}{ Mean } & \multirow{2}{*}{ Std. Erorr } & \multirow{2}{*}{ Coef.Var } \\
\hline & & $\min$ & $\max$ & & & \\
\hline 1.Phrynoidis aspera & 67 & 3.29 & 16.2 & 10.16 & 3.15 & 9.95 \\
\hline 2.Leptobrachium hasseltii & 64 & 2.12 & 7.50 & 3.83 & 1.28 & 1.64 \\
\hline 3.Hylarana chalconota & 50 & 1.30 & 9.25 & 4.80 & 1.50 & 2.27 \\
\hline 4.Odorrana hosii & 41 & 3.61 & 14.2 & 6.88 & 2.51 & 6.30 \\
\hline 5.Microhyla achatina & 25 & - & - & - & - & - \\
\hline 6.Limnonectes kuhlii & 18 & 2.72 & 7.16 & 5.14 & 1.35 & 1.82 \\
\hline 7.Duttaphrynus melanostictus & 6 & 5.10 & 8.51 & 6.75 & 1.42 & 2.02 \\
\hline 8.Occydozyga sumatranus & 4 & 1.97 & 3.61 & 2.84 & 0.67 & 0.45 \\
\hline 9.Fejervarya limnocharis & 3 & 2.26 & 4.99 & 3.72 & 1.37 & 1.894 \\
\hline 10.Rhacophorus reindwardtii & 2 & 4.00 & 5.58 & 4.79 & 1.11 & 1.248 \\
\hline 11.Polypedates leucomystax & 1 & 5.48 & 5.48 & 5.48 & - & - \\
\hline
\end{tabular}

Dari tabel di atas dapat diketahui terdapat3 jenis amfibi yang mendominasi, yaitu Phrynoidis aspera, Leptobrachium hasseltii, dan Hylarana chalconota. Struktur populasi dan aktivitas jenis anura yang ada di DAS Gunung Kelir diilustrasikan dalam gambar 1. Perbandingan jumlah antara berudu, juvenile, katak jantan, dan betina di setiap lokasi sampling disajikan dalam gambar 2. Selanjutnya untuk distribusi anura berupa peta persebaran letak amfibi yang hidup pada DAS Gunung Kelir ketika dijumpai saat sampling dapat dilihat pada gambar 3 . Penelitian ini juga berhasil mendata berbagai aktivitas amfibi di sungai ketika sampling. Tercatat enam aktivitas amfibi, di mana dari keenam aktivitas yang dicatat, yaitu diam 
$(45 \%)$, bersuara (27\%), loncat (18\%), berenang (5\%), ampleksus (3\%), dan makan (2\%). Diam dan bersuara merupakan aktivitas yang paling banyak dilakukan.

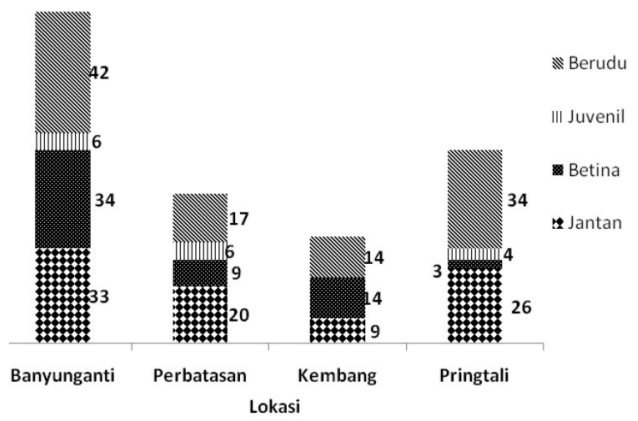

Gambar 2.

Rasio umur anura yang ditemukan pada setiap lokasi
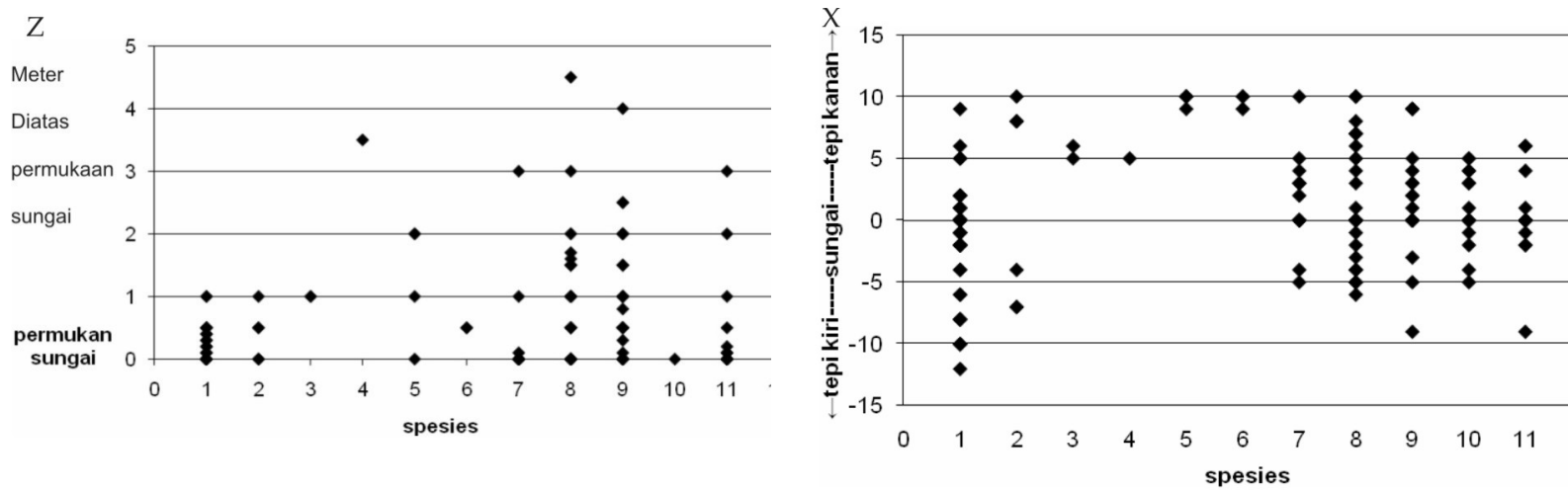

Gambar 3

Distribusi amfibi di sepanjang DAS Gunung Kelir. Keterangan 1) Phrynoidis aspera, 2) Duttaphrynus melanostictus 3) Rhacophorus reindwardtii, 4) Polypedates leucomystax, 5) Occydozyga sumatranus, 6) Fejervarya limnocharis, 7) Limnonectes kuhlii, 8) Odorrana hosii, 9) Hylarana chalconota, 10) Microhyla achatina dan 11) Leptobrachium hasseltii (Z) Posisi vertikal persebaran amfibi dimana permukaan air sungai dianggap sebagai titik 0

(X) Posisi horizontal persebaran amfibi berdasarkan posisi melebar sungai, di mana tepi kiri sungai dianggap titik 0

Data parameter lingkungan selama penelitian meliputi kerapatan relatif vegetasi, suhu rata-rata, $\mathrm{pH}$ rata-rata, lebar dan dalam sungai di masing-masing lokasi sampling disajikan pada Tabel 2 sebagai berikut:

Tabel 2 .

Parameter lingkungan yang terukur dimasing-masing lokasi

\begin{tabular}{|c|c|c|c|c|c|c|c|c|c|c|}
\hline \multirow{2}{*}{ Lokasi } & \multirow{2}{*}{$\mathrm{n}$} & \multicolumn{2}{|c|}{ Dalam (m) } & \multicolumn{2}{|c|}{ Lebar (m) } & \multicolumn{2}{|c|}{ Suhu rerata } & \multirow{2}{*}{$\mathrm{pH}$ air } & \multirow{2}{*}{ vegetasi } & \multirow{2}{*}{ substrat } \\
\hline & & $\min$ & $\max$ & $\min$ & $\max$ & air & udara & & & \\
\hline Banyunganti & 11 & 0.1 & 1 & 3.5 & 6 & 21 & 22.5 & 6 & tertutup kanopi & batuan kapur \\
\hline Perbatasan & 6 & 0.1 & 1.5 & 3.5 & 7 & 21 & 22.5 & 6.3 & tertutup kanopi & b.kapur,pasir \\
\hline Kembang & 5 & 0.1 & 2 & 4 & 7 & 22 & 23 & 6.3 & kanopi renggang & b.kapur,pasir \\
\hline Pringtali & 3 & 0.1 & 0.5 & 9 & 10 & 22 & 23.5 & 6.6 & tidak ada kanopi & b. cadas besar \\
\hline
\end{tabular}


Pada sampling pertama berhasil didapatkan 8 spesies dengan 1 jenis yaitu Microhyla achatina endemik Jawa. Pada sampling kedua bertambah menjadi 11 spesies. Pada sampling ketiga hingga sampling terakhir tidak ditemukan penambahan spesies anggota Ordo Anura di sepanjang aliran sungai Gunungkelir.

Berdasarkan gambar 1, diketahui indeks diversitas herpetofauna di sepanjang aliran sungai Gunungkelir memiliki kisaran indeks diversitas dari 0,5 hingga 2,19. Indeks diversitas lokasi IV yaitu Pringtali memiliki keanekaragaman paling tinggi $(2,19)$, sedangkan kedua pada lokasi II, yaitu Perbatasan dan ketiga pada lokasi III, yaitu Kembang. Hal ini mendukung teori Primack bahwa komposisi komunitas dan keanekaragaman jenis lebih tinggi pada dataran rendah daripada dataran tinggi dan kelimpahan jenis semakin berkurang dengan bertambahnya ketinggian (Primack, dkk: 1998).

Berdasarkan perbedaan jenis herpetofauna yang ditemukan di masingmasing lokasi, maka antara lokasi satu dengan lokasi yang lain dapat kita hitung berapa besarkah kesamaan jenis herpetofauna yang ada pada masing-masing lokasi. Hal ini berguna untuk mengetahui perbedaan persebaran herpetofauna di masing-masing lokasi, jika semakin tinggi kesamaan jenis herpetofauna yang ada, maka kemungkinan besar habitatnya memiliki kondisi yang sama. Akan tetapi, tentu saja hal ini tidak dapat menjadi patokan dasar. Hasil analisis indeks dissimilaritas Bray Curtis menunjukkan antara lokasi I (Banyunganti) dengan lokasi IV (Pringtali) memiliki kemiripan komposisi jenis yaitu 0,14 (mendekati 0). Komposisi jenis herpetofauna yang paling berbeda yaitu antara loaksi I (Banyunganti) dengan lokasi III (Kembang) yaitu 0,87. Besarnya kesamaan jenis menandakan kondisi dan karakterisitik habitat kedua lokasi pengamatan memiliki kesamaan.
Pada Tabel 1, dapat dilihat bahwa jenis anura yang paling banyak ditemukan adalah Phrynoidis aspera (67 individu), Leptobrachium hasseltii (64 individu) dan Hylarana chalconota (50 individu). Ketiga jenis tersebut mudah dijumpai karena ketiganya memiliki sifat sangat tergantung pada air (dapat dilihat gambar 3) dan memiliki mekanisme pertahanan diri yang bagus dari predator. Jenis yang paling sedikit dijumpai adalah Polypedates leucomystax dan Rhacophorus reindwardtii. Hal ini dikarenakan keduanya memiliki pergerakan yang cepat, pintar berkamuflase, dan lebih senang berada di dahan pohon yang tinggi (dapat dilihat gambar 3) sehingga sangat sulit untuk dijumpai, apalagi saat-saat musim kemarau. Berdasarkan IUCN Red List, kesemua anura yang teridentifikasi termasuk dalam kategori Near Threatened dan Least Concern. Dengan diketahui statusnya dapat memberikan informasi bahwa anura yang ada di Sepanjang Sungai Gunung Kelir tidak ada yang tergolong kritis ataupun terancam punah.

Dari Tabel 1 juga dapat diketahui bahwa Phrynoidis aspera, Leptobrachium hasseltii, dan Hylarana chalconota yang dijumpai dilokasi penelitian memiliki ukuran tubuh yang relatif besar. Iskandar (1998) mengatakan bahwa kisaran SVL Phrynoidis aspera yang ditemukan di Jawa maksimal $12 \mathrm{~cm}$, Leptobrachium hasseltii maksimal $7 \mathrm{~cm}$, dan Hylarana chalconota yang ditemukan di Jawa maksimal $6 \mathrm{~cm}$. Van Kampen (1923) mengatakan bahwa kisaran ukuran SVL Phrynoidis aspera yang ditemukan di kepulaun indo-australia maksimal 26 $\mathrm{cm}$, Leptobrachium hasseltii maksimal $7 \mathrm{~cm}$, dan Hylarana chalconota yang ditemukan di kepulaun indo-australia maksimal $6 \mathrm{~cm}$. Perbedaan ukuran tubuh (SVL) ini disebabkan oleh adanya perbedaan kondisi habitat pada masing-masing lokasi. Menurut Chruch (1915), faktor yang mempengaruhi perbedaan ukuran ukuran tubuh (SVL) meliputi kualitas habitat, ketersediaan pakan, dan kualitas makanan. 
Struktur komunitas anura yang ditemukan di lokasi Banyunganti paling banyak berupa populasi berudu, lalu populasi dewasa dan paling sedikit berupa juvenile (gambar 2). Begitu juga pada lokasi Pringtali, struktur populasinya paling banyak berupa populasi berudu, lalu diikuti populasi dewasanya, dan paling sedikit berupa juvenile. Struktur komunitas ini menandakan bahwa pada bulan Januari-April masih merupakan musim berkembang biaknya anura yaitu selama musim penghujan. Berbeda dengan struktur komunitas di lokasi perbatasan dan di dusun Kembang, di kedua lokasi ini populasi yang paling banyak berupa anura dewasa dan yang paling sedikit berupa berudu. Hal tersebut dikarenakan pada lokasi Banyunganti dan Pringtali banyak terdapat jeluk dengan kedalaman antara 0,1-1 m serta memiliki arus yang tidak kencang dan substratnya tidak berpasir (dapat dilihat tabel 2). Ini sangat mendukung untuk dijadikan tempat berkembang biak dan berkembangnya berudu. Berbeda denganlokasi perbatasan dan di dusun Kembang, selain banyak terdapat air terjun kecil, arusnya deras dan jeluknya sedikit, dan di kedua lokasi ini substratnya berpasir (dapat dilihat tabel 2). Hanya sedikit tempat yang cocok untuk berkembang biak dan tempat berkembangnya berudu. Dari kedua lokasi ini penjumpaan berudu lebih sedikit dibandingkan penjumpaan dewasanya. Kebanyakan berudu di kedua lokasi ditemukan di genangan air tidak jauh dari sungai.

Sexual dimorphisme merupakan adanya perbedaan nyata variasi morfologiantarajantan dan betina. Variasi morfologi tersebut dapat dijadikan sebagai salah satu pengidentifikasi jenis kelaminnya. Dari hasil analisis T-test adanya sexual dimorphisme dengan tingkat signifikan 99\% terdapat pada Phrynoidis aspera $(\mathrm{t}=5.994, \mathrm{p}<0,01)$, Limnonectes kuhlii $(\mathrm{t}=6.486$, $\mathrm{p}<0,01)$, Odorrana hosii $(\mathrm{t}=6.889, \mathrm{p}<0,01)$ dan Hylarana chalconota $(\mathrm{t}=4.226, \mathrm{p}<0,01)$. Sexual dimorphisme secara rinci keempat amfibi tersebut antara lain: Phrynoidis aspera jantan memiliki SVL 3.5-10.3 dengan mean 8.7 dan yang betina SVL10.05-16.2 dengan mean 12.9; Limnonectes kuhlii jantan memiliki SVL 2.72-4.6 dengan mean 3.9 dan yang betina SVL 4.167.16 dengan mean 5.9; Odorrana hosii jantan memiliki SVL 3.9-6.5 dengan mean 5.1 dan yang betina SVL 6.6-14.2 dengan mean 8.8; dan Hylarana chalconota jantan memiliki SVL 2.6-5.7 dengan mean 3.8 dan yang betina SVL 4.3-9.25 dengan mean 5.7 .

Rasio perbandingan antara jantan dan betina di masing-masing lokasi juga sangat menentukan keberlangsungan populasi anura yang akan datang. Untuk jenis Phrynoidis aspera rasio kelamin jantan dan betinanya adalah 1:0,27; Duttaphrynus melanostictus rasio kelamin jantan dan betinanya adalah 1:0,33; rasio kelamin Occydozyga sumatranus adalah 1:2, rasio kelamin Fejervarya limnocharis adalah 0:1, rasio kelamin Limnonectes kuhlii adalah 1:1,83, rasio kelamin antara jantan dan betina Odorrana hosii adalah 1:095, sedangkan Hylarana chalconota rasio kelamin jantan dan betinanya adalah 1: 0,58 dan rasio kelamin Leptobrachium hasseltii adalah 1: 0,38. Jika dilihat dari jumlah individu yang ditemukan serta dari rasio perbandingan antara jantan dan betina, dapat diperkirakan bahwa Phrynoidis aspera dan Leptobrachium hasseltii merupakan jenis anura yang rentan terhadap ancaman aktivitas manusia. Hal ini dikarenakan rasio antara jantan dan betinanya tidak seimbang. Jika terdapat aktivitas manusia yang dapat menurunkan populasi betinanya, maka kemungkinan besar populasi dari kedua jenis anura dilokasi tersebut perlahan-lahan dapat menurun seiring dengan semakin kecilnya kemungkinan katak jantan kawin dengan betina.

Dari hasil penelitian juga didapat bahwa pola aktivitasnya anura yang paling tinggi frekuensinya adalah aktivitas berdiam diri (sebesar 45\%) dan bersuara (sebesar 27\%). Kemungkinan aktivitas berdiam diri ini adalah dalam rangka mencari makanan sedangkan aktivitas bersuara kemungkinan dalam rangka menemukan pasangannya 
dan berkomunikasi dengan individu lainnya. Menurut O'Shea \& Halliday (2001) bahwa pada umumnya perilaku mencari makan pada anura adalah "duduk dan menunggu". Akan tetapi, dengan perilaku semacam ini juga menjadikan anura sebagai prey yang mudah ditemukan bagi fauna yang lainnya. Pola aktivitas dan distribusi anggota Ordo Anura yang ditemukan pada lokasi penelitian dipengaruhi oleh lingkunganya. Faktor yang mempengaruhi dapat berupa fisik (suhu, ketinggian, cahaya matahari, dan kelembaban) maupun biologi (morfologi, anatomi, pemangsa, ketersediaan makanan, dan kompetisi). Masing-masing jenis akan merespon faktor-faktor tersebut secara berbeda (O'Shea \& Halliday, 2001; Stebbins, \& Cohen, 1995). Dari uji korelasi Pearson, faktor lingkungan berupa suhu udara, suhu air, dan $\mathrm{pH}$ ternyata tidak secara signifikan berpengaruh terhadap kekayaan jenis di masing-masing titik sampling. Hal ini dapat dipahami karena berdasarkan hasil pengukuran hanya ditemukan sedikit perbedaan antar- titik sampling. Selain itu faktor-faktor lain seperti cahaya matahari, curah hujan, kelembaban, kelimpahan pemangsa, ketersediaan makanan, dan kompetisi tidak ikut diukur. Padahal antara satu faktor lingkungan dengan faktor lingkungan yang lain saling mempengaruhi dan memiliki hubungan yang sangat komplek

\section{SIMPULAN}

Dari penelitian ini telah diidentifikasi 11 jenis ordo anura yang terdiri dari 2 jenis anggota famili Bufonidae, 2 jenis anggota famili Rhacophoridae, 1 jenis anggota famili Megophridae, 1 jenis anggota famili Microhylidae, 2 jenis anggota famili Ranidae, dan 3 jenis anggota famili Dicroglossidae. Struktur populasi didominasi oleh berudu $38 \%$, lalu jantan $35 \%$ dan betina $21 \%$, dan sisanya juvenil. Jenis anura yang melimpah adalah Phrynoidis aspera (67 individu), Leptobrachium hasseltii (64 individu), dan Hylarana chalconota (50 individu).

\section{DAFTAR PUSTAKA}

Blaustein, A. R., Hatch, A. C., Belden, L. K., Scheessele, E. \& Kiesecker, J. M., 2003, Global change: Challenges facing amphibians". In: Amphibian conservation . Smithsonian Books, Washington,D.C. hlm 187-198

Brower JE and J. Zarr, 1997, Field and Laboratory For General Ecology, W.M.C Brown Company Publishing, Portugue, IOWA

Carrey, C., W.R. Heyer, J. Wilkinson, R.A.Alford, J.W.Artnzen, T.Halliday, L.Hungeford, K.R.Lips, E.M. Middleton, S.A Orchard \& A.S. Rand., 2001, Amphibian decline and environmental changes: Use of remote-sensing data to identify environmetal correlates. Conservation Biology 15(4): 903-913.

Church, G., 1959, "Size variation in Bufo melanostictus from Java and Bali (Amphibian)". Truebia. 25, 113-126

Corn, P. S., 2005, "Climate change and amphibians. Animal Biodiversity and Conservation", 28 (1), 59-67.

Cushman, S.A., 2006, "Effects of habitat loss and fragmentation on amphibians: A review and prospectus". Biological Conservation 128, 231-240.

Field, J. G. \& McFarlane, G., 1968, “Numerical methods in marine ecology". 1. A quantitative 'similarity' analysis of rocky shore samples in False Bay, South Africa. Africana 3 (2), 119-137

Frost, DR., T. Grant, JN. Faivovich, RH. Bain, A. Haas, CFB. Haddad, RO. Desa, A. Channing, M. Wilkinson, SC. Donnellan, CJ. Raxworthy, JA. Campbell, BL. Blotto, P. Moler, R. Drewes, RA. Nussbaum, JD. Lynch, DM. Green, \& WC. Wheeler, 2006, "The amphibian tree of life", Bulletin of the American Museum of Natural History, 297. 
Goobridge, B., 1992, “Global Biodiversity Status of The Earth's Living Resources". A Report Compiled by The World Conservation Monitoring. India. hlm 66 .

Gardner, T., 2001, "Declining amphibian populations: A global phenomenon in conservation biology". Animal Biodiversity and Conservation 24(2), 25-44

Iskandar, D.T. ,1998. “The Amphibian of Java and Bali". Bogor.

Iskandar, D.T., 2006., "Checklist of Southeast asian and New Guinean amphibian". (in press).

IUCN, Conservation International, and Nature Serve. 2008. Red List Category [online] 2008. Avalaible from: URL: http:// www.globalamphibians.org. accessed February 25, 2008.

Kampen, P.N. 1923. "The amphibia of the Indo-Australian Archipelago". Leiden, E.J. Brill.

Kurniati, H. 2006. Jenis-jenis kodok di Taman Nasional Gunung Halimun yang termasuk kategori dafter merah IUCN. Fauna Indonesia 6(1): 31-34
Kusrini, M.D., L.F. Skerratt, S. garland, 1. Berger \& W. Endarwin, 2008, "Chytridiomycosis in frog Mount Gede Pangrango", Indonesia. Diseases of Aquatic Organisms 87:187-194.

O'Shea, M. \& T. Halliday., 2001, “Reptiles and Amphibians". London. 256 p.

Prihantono, S., 2007. Keanekaragaman Herpetofauna (Ordo Anura dan Squamata) Nocturnal di Sungai Denggung dan sungai Gadjah Wong, Daerah Istimewa Yogyakarta. Seminar. Yogyakarta, Fakultas Biologi. Universitas Gadjah Mada. Tidak dipublikasikan.

Primack, Richard B., Jatna Supriatna, M. Indrawan dan P. Kramadibrata., 1998, Biologi Konservasi. Jakarta, Yayasan Obor Indonesia. Jakarta. hlm 345

Stuart, S.N., J.S. Chanson, N.A. Cox, B.E. Young, A.S.L. Rodrigues, D.L. Fischman and R.W. Waller., 2004. "Status and trends of amphibian declines and extinctions worldwide". Science 306, 1783-1786

Stebbins, R. C. \& Cohen, N. W., 1995. A natural history of amphibians. Princeton University Press, Princeton, New Jersey. 